\title{
KeV ION BEAM INDUCED SURFACE MODIFICATION OF SiC HYDROGEN
} SENSOR

\author{
C. I. MUNTELE*, D. ILA*, E. K. WILLIAMS*, D. B. POKER**, D. K. HENSLEY** \\ *Center for Irradiation of Materials, Alabama A\&M University, Normal, AL 35762-1447, USA \\ **Solid State Division, Oak Ridge National Laboratory, Oak Ridge, TN 37831, USA
}

\begin{abstract}
Silicon carbide, a wide-bandgap semiconductor, is currently used to fabricate an efficient high temperature hydrogen sensor. When a palladium coating is applied on the exposed surface of silicon carbide, the chemical reaction between palladium and hydrogen produces a detectable change in the surface chemical potential. Rather than applying a palladium film, we have implanted palladium ions into the silicon face of $6 \mathrm{H}, \mathrm{n}$-type $\mathrm{SiC}$ samples. The implantation energies and fluences, as well as the results obtained by monitoring the current throught the sample in the presence of hydrogen are included in this paper.
\end{abstract}

\section{INTRODUCTION}

In the past few years there has been an increased interest in the field of gas sensors that can operate in harsh environments such as hot engine controls for aerospace and automobile applications, or process gas monitoring. The requirement of operating in high temperature environments brought silicon carbide into attention, for its remarkable properties. Because of its outstanding thermal stability, silicon carbide, that is a semiconductor material with a wide bandgap and low intrinsic carrier concentration, can operate as a semiconductor potentially up to $1000^{\circ} \mathrm{C}[1,2]$. The presence of a catalytic metal such as palladium onto (or into) silicon carbide results in a Schottky diode behavior. When a gas containing hydrogen (such as methane, propylene, $\mathrm{H}_{2}$ mixed in an inert gas etc.) passes across the surface containing palladium, the hydrogen is separated from its previous chemical bond in the gas and linked to palladium. This results in changing the space charge region surrounding the metal clusters, which in turn affect the conductivity of the crystal. This change in conductivity is measured and can be correlated to surface concentrations of catalyst and to the concentration of the sampled gas in the environment.

\section{EXPERIMENT}

Rather than depositing palladium onto the surface of silicon carbide as in ref. [3], for this study we implanted palladium ions through the silicon face of $6 \mathrm{H}, \mathrm{n}$-type (nitrogen doped), $3.5^{\circ}$ off-axis orientation, silicon carbide samples provided by Cree Research, Inc. The samples were implanted at $500^{\circ} \mathrm{C}$, in order to minimize the induced implantation dammages, to fluences between $3 \times 10^{14}$ at $/ \mathrm{cm}^{2}$ and $3.2 \times 10^{16}$ at $/ \mathrm{cm}^{2}$, and implantation energies of $70 \mathrm{keV}$ and $130 \mathrm{keV}$. The implantation energies were chosen using the SRIM code [4] in order to get high surface concentrations of $\mathrm{Pd}$ ions. Also, from the same code, the approximated implantation range was established as being $40 \mathrm{~nm}$ and $65 \mathrm{~nm}$ (see figure 7).

The current measurements were done using a Keithley model 595 IV/CV meter interfaced to a computer, for several temperatures near $23,70,145,215^{\circ} \mathrm{C}$ in a closed gas environment. Voltages of $\pm 1 \mathrm{~V}$ were applied on the backside of the sample, and the current was 
measured using a probe on several places on the implanted side. The temperature was also monitored in order to correct for current fluctuations due to temperature changes. For this experiment, air was cycled with an $\mathrm{H}_{2}-\mathrm{Ar}$ gas mixture with $4 \%$ hydrogen, and the cycles were chosen to be 2 minutes in length (a compromise between the signal rise time and the length for a complete measurement of 7 cycles). A drawing of the experimental setup is shown in Fig. 1 . The metallic contacts were made out of gild copper, and the insulator was thick Teflon, so that the capacitance with the bottom side of the aluminum enclosure (connected to the common ground as a Faraday cage) was negligible.

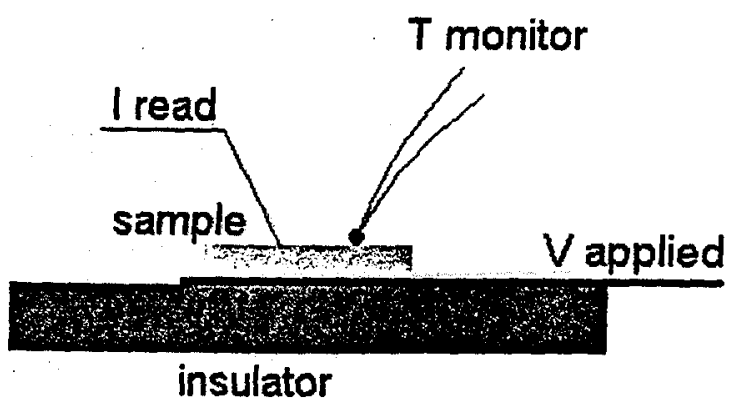

Figure 1. Schematic view of the setup.

\section{RESULTS}

Figures 2 through 5 show that at room temperature $\left(23^{\circ} \mathrm{C}\right)$ the current increases in the presence of the $4 \% \mathrm{H}_{2}$ in the $\mathrm{H}_{2}$-Ar mixture, for all of the $\mathrm{SiC}$ implanted samples. When the $\mathrm{H}_{2}-$ Ar environment is replaced by air, the current reverts to its initial value. At higher substrate temperatures, the difference between the current read-out for $\mathrm{H}_{2}-\mathrm{Ar}$ ambient and air ambient decreases as we approach $60^{\circ} \mathrm{C}$ to $84^{\circ} \mathrm{C}$ where it becomes zero. By increasing the temperature, one can clearly see from these figures that the current in the presence of $\mathrm{H}_{2}-\mathrm{Ar}$ gas becomes definitely smaller than when air is present. For comparison, measurements performed on blank $\mathrm{SiC}$ samples revealed no current fluctuation with the gas change for any temperature in the range $23^{\circ} \mathrm{C}-240^{\circ} \mathrm{C}$. Our implanted sensor at high temperatures shows an opposite behavior in the current while exposed to hydrogen, relative to sensors reported in the literature $[3,5,6]$ for $\mathrm{SiC}$ with palladium deposited on the surface. There, the current in the presence of hydrogen is more for every temperature level, and reverts to the initial value when air is supplied instead of hydrogen.

A similar behavior was observed for both positive and negative voltages applied (the currents for negative voltage are shown in the graphs in absolute values). For absolute voltages above $1.2 \mathrm{~V}$, the $\mathrm{p}-\mathrm{n}$ junction breaks down, and no more sensing behavior can be observed.

\section{CONCLUSIONS}

From the results that we have so far, we could not observe a clear dependence of the current according to the level of implantation dose, or energy. However, one can say that the current for samples \#2 (low fluence) is smaller than that of the sample \#8 (high fluence, same high energy), but the order is reversed for samples implanted at lower energy and similar fluences. Also, the fact that after the $p$-n junction breakdown no more sensing behavior can be observed makes us believe that the sensing properties are related to the rectifying properties of 
the device rather than strictly due to the modification in the conductivity of palladium, or palladium hydride. If we accept this observation, then the similar behavior for both positive and negative voltages applied might be due to a structure more like $n-p-n$ rather than simple $p-n$ junction. This is expected, since the crystallinity of the $\mathrm{SiC}$ layer remains unchanged due to high temperature implantation.

The relatively long rise time that can be observed on all the graphs presented in figures 2 to 5 is mainly due to the fact that the hydrogen has to diffuse through the surface layer to reach the deeper palladium ions as the ones close to the surface become saturated. Similarly, when air is introduced, the diffusion process is reversed, from the depth to the surface, resulting in the long recovery time. The recovery process is based on the capability of removal of the hydrogen that was adsorbed in the device. Two processes occur: the chemical afinity for hydrogen by the oxygen in the air, and the outgassing due to the device's operation at elevated temperatures. At room temperature the first process is dominant, while the outgassing begins to behave at temperatures above $100^{\circ} \mathrm{C}$.

Further measurements, with a better remote controlled experimental setup, are underway at this time in order to obtain a precise behavior.

\section{ACKNOWLEDGEMENTS}

This work is supported by the Center for Irradiation of Materials at Alabama A\&M University and NASA-LeRC Contract No. NAG3-2123. The work at ORNL was sponsored by the Division of Materials Science, US Department of Energy, under Contract DE-AC05960R22464 with Lockheed Martin Energy Research Corp.

\section{REFERENCES}

1. G. W. Hunter, P. G. Neudeck, G. D. Jefferson, G. C. Madzsar, C. C. Liu, Q. H. Wu, Report E7773 NASA, 1993.

2. G. Muller, G. Krotz, E. Niemann, SiC for sensors and high-temperature electronics, Sensors and Actuators, A, 43, 1-3 (1994) 259-268.

3. M. A. George, M. A. Ayoub, D. Ila, D. J. Larkin, Elevated temperature silicon carbide chemical sensors, Spring MRS Meeting, San Francisco, 1999.

4. J. F. Ziegler, J. P. Biersack, U. Littmark, The Stopping and Range of Ions in Solids, Pergamon Press, NY, 1985.

5. G. W. Hunter, P. G. Neudeck, L. Y. Chen, D. Knight, C. C. Liu, Q. H. Wu, Silicon carbide based hydrogen and hydrocarbon gas detection, Joint Propulsion Conference and Exhibit, 1995, San Diego, CA.

6. L. Y. Chen, G. W. Hunter, P. G. Neudeck, D. Knight, C. C. Liu, Q. H. Wu, SiC-based gas sensors, The $190^{\text {th }}$ Meeting of the Electron Society, 1996, San Antonio, TX. 

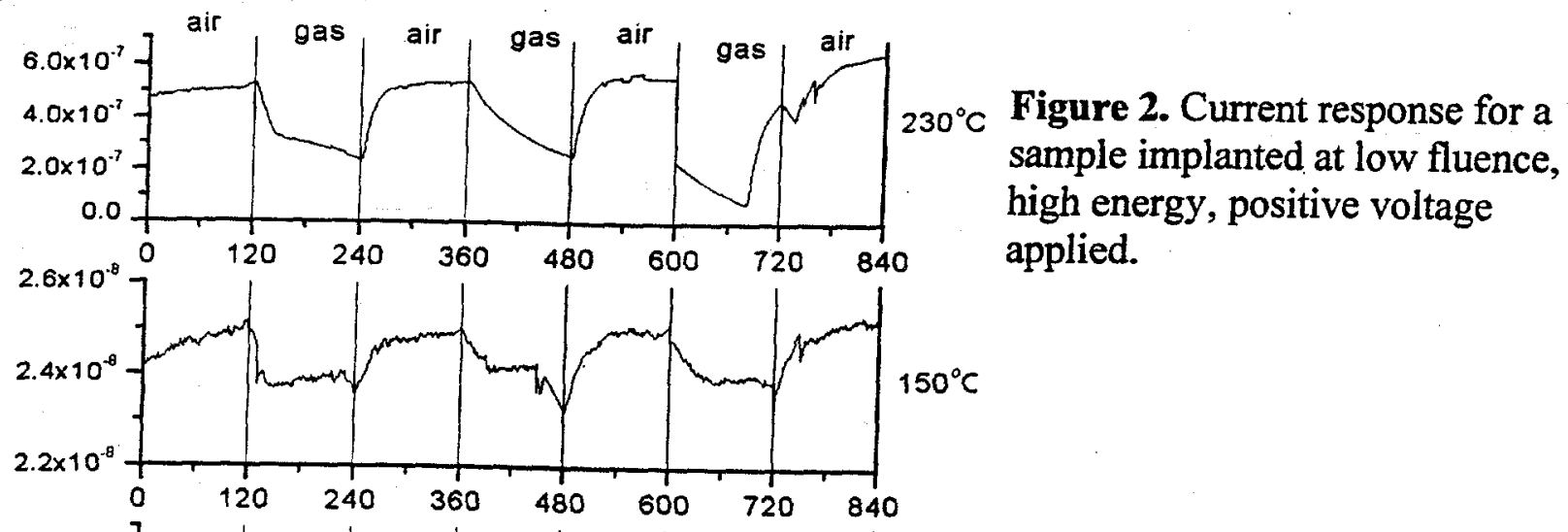
applied.
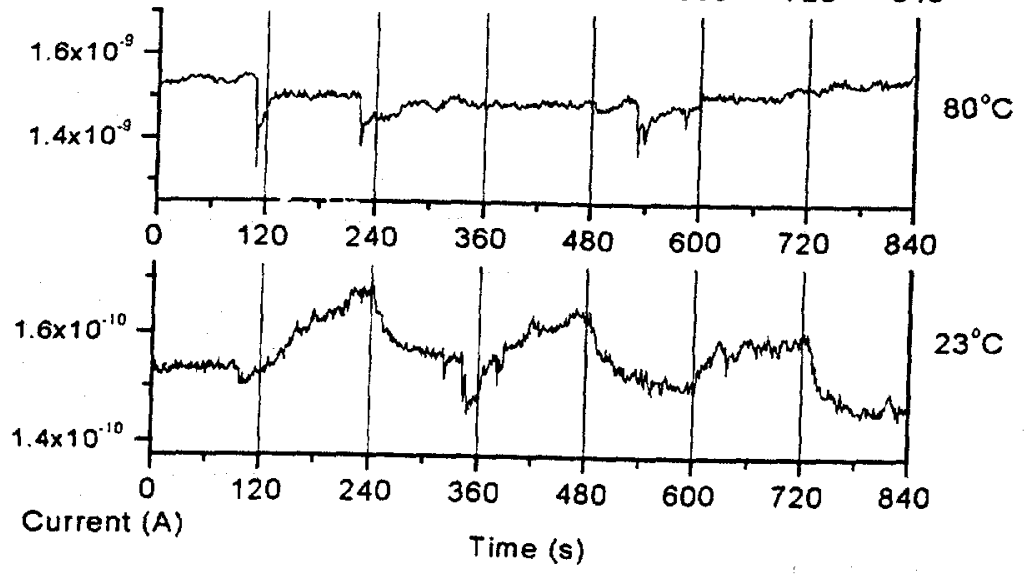

Sample 2, fluence:3e+14,E=130 keV, $U=-1 V$
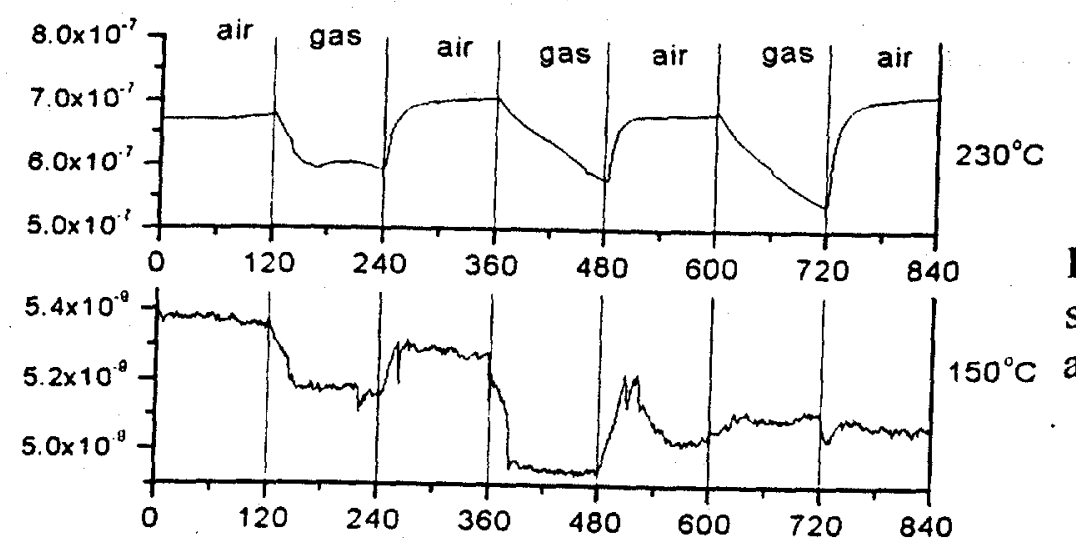

Figure 3. Current response for the same sample, negative voltage applied.

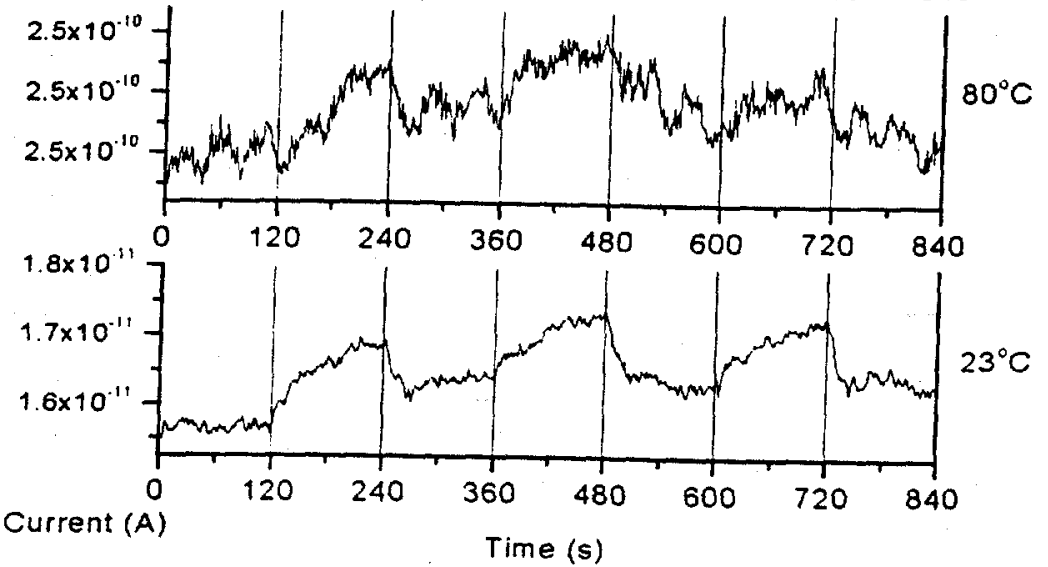




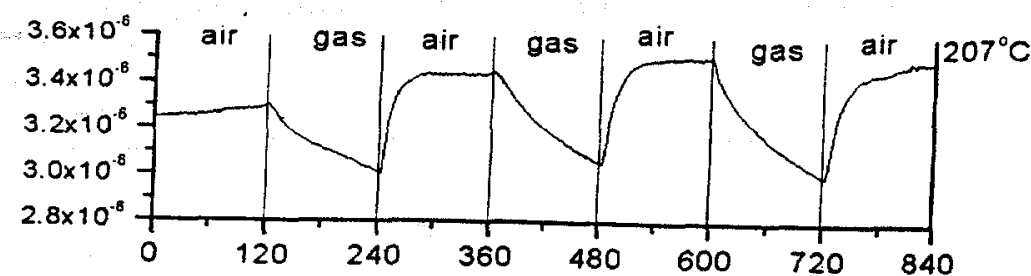

Figure 4. Current response for a sample implanted at high fluence, high energy, positive voltage applied.
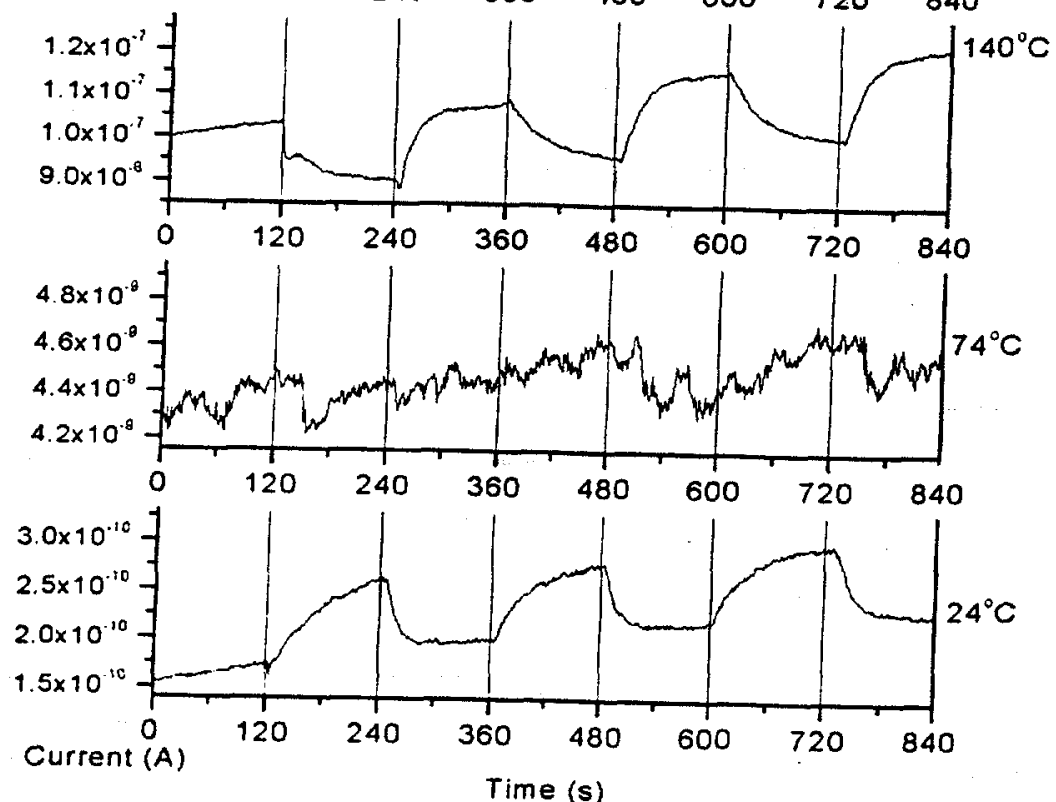

Sample 8, fluence: $3.2 e+16, E=130 \mathrm{keV}, U=-1 \mathrm{~V}$

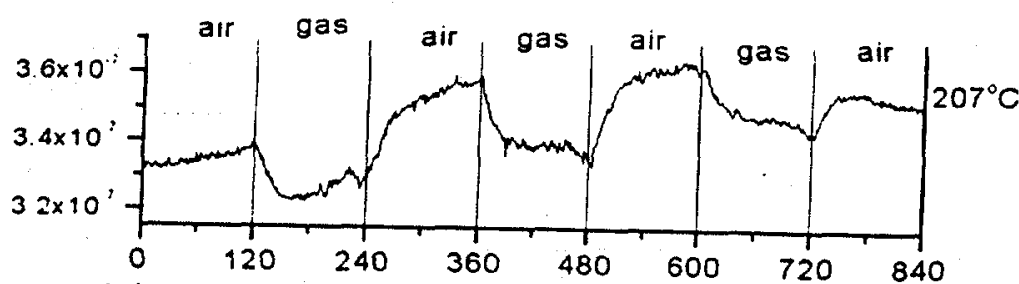

Figure 5. Current response for the same sample, negative voltage applied.
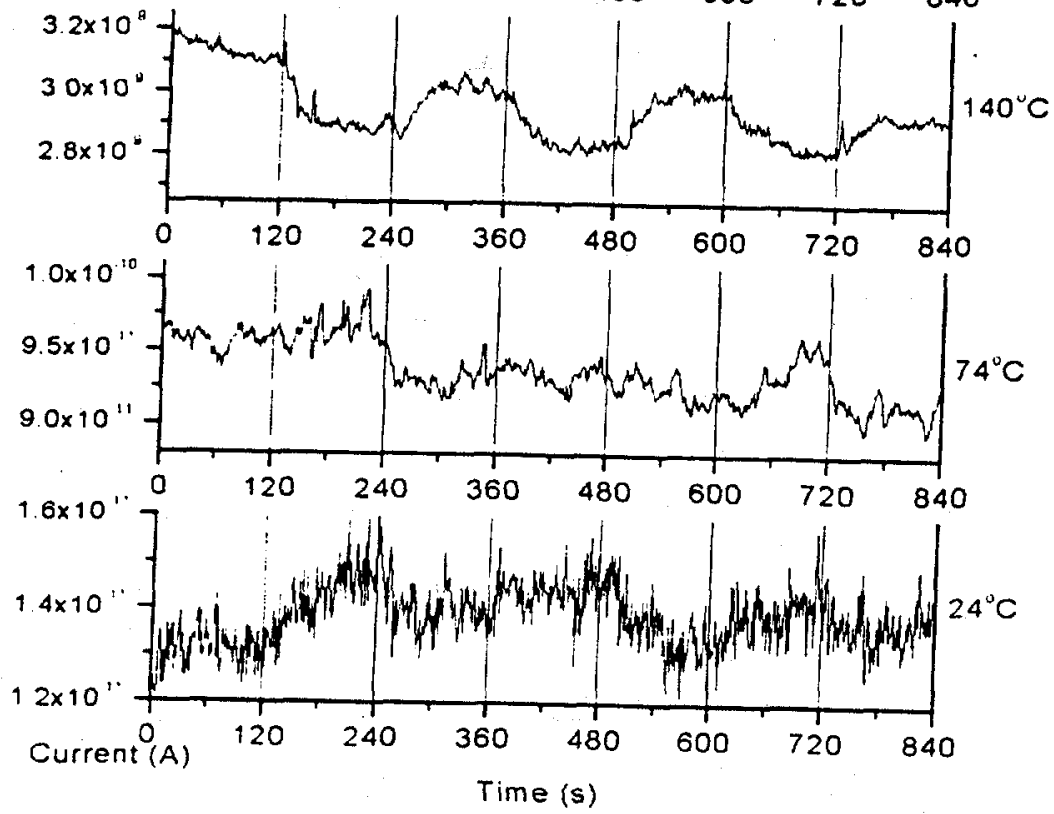


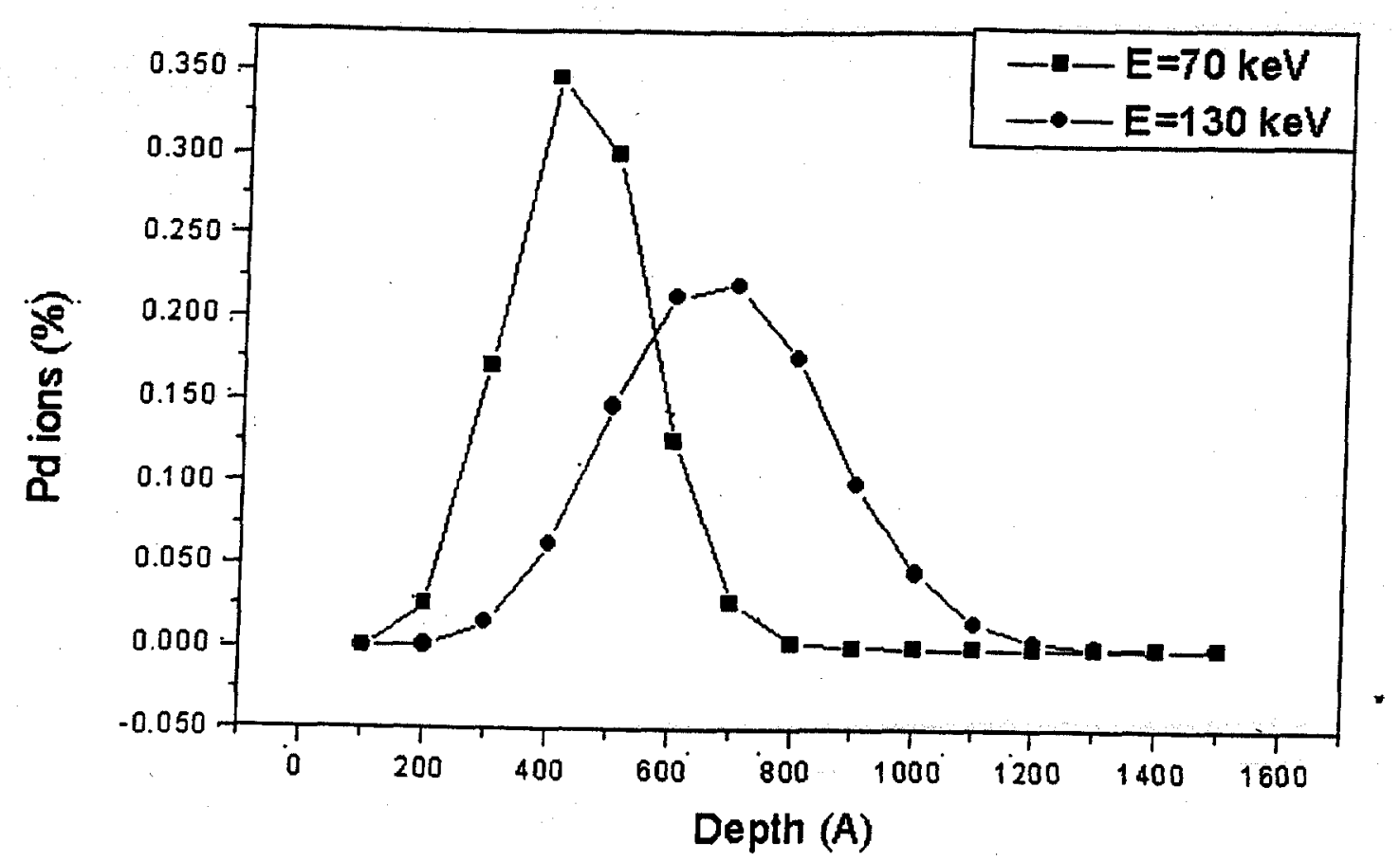

Figure 6. SRIM simulation for the range of Pd ions in SiC (10 000 events for each energy). 